\title{
Dissociation of Enhanced Ornithine Decarboxylase Activity and Optic Nerve Regeneration in Goldfish
}

\author{
SHINICHI KOHSAKA*, ANNE M. HEACOCK, PAUL D. KLINGER, \\ RAFFAELE PORTA** and BERNARD W. AGRANOFF*** \\ Neuroscience Laboratory, Mental Health Research Institute, The University of Michigan, \\ Ann Arbor, MI 48109 (U.S.A.)
}

(Accepted November 12th, 1981)

Key words: goldfish retina — optic nerve regeneration — ornithine decarboxylase - polyamine

The significance of a previously observed increase in retinal ornithine decarboxylase (ODC, EC 4.1.1.17) following optic nerve crush was investigated in goldfish using a specific irreversible inhibitor of ODC, $\alpha$-difluoromethylornithine (DFMO). Retinal ODC activity and putrescine levels were reduced $80 \%$ and $40 \%$, respectively, by intraperitoneal injection(s) of DFMO. In fish in which the right optic nerve was crushed and DFMO was injected at the time of crush, at 2 days and at 4 days later, retinal ODC levels were maximally decreased after the third injection and returned to normal levels by 14 days post-crush (PC).

Retinal tubulin synthesis was examined at 10 days PC. No difference in the post-crush/normal ratio of tubulin synthesis was observed between saline-injected and DFMO-injected groups. Neuritic extension was also examined in retinal explant cultures from 11-day PC retina. The neuritic growth index of DFMO-treated retinas did not differ from that of control retinas. Behavioral studies revealed no difference in the rate of recovery of vision between the two groups. Similar results were obtained in experiments using fish maintained in a $0.1 \%$ DFMO solution.

These results suggest that the increase in retinal ODC associated with nerve crush does not play a causal role in restoration of function.

\section{INTRODUCTION}

Retinal ganglion cells of many teleosts and amphibians can regenerate functional axons following optic nerve injury ${ }^{6}$. Previous work in this laboratory on the goldfish retina following crush of its optic nerve has demonstrated unilateral enhancement of RNA and RNA precursor metabolism ${ }^{1,2,3,12}$ as well as of de novo synthesis of retinal microtubular protein ${ }^{8}$.

Polyamines such as putrescine, spermidine and spermine have long been implicated in the initiation and maintenance of rapid cell growth ${ }^{11,23,30}$. A special role in the nervous system has been suggested by the report that putrescine is transported axonally in the goldfish by newly regenerated optic nerve, but not by intact optic nerve ${ }^{10}$. Recently, we found a generalized increase in ornithine decarboxylase (ODC) in the goldfish following unilateral optic nerve crush ${ }^{13}$. Although increases are found in both post-crush (PC) and normal $(\mathrm{N})$ retinas as well as in brain and kidney, they are significantly higher in PC retina than in $\mathrm{N}$ retina ${ }^{13}$. Furthermore, employing the retinal explant culture, we have demonstrated that addition of diaminopropane, a specific inhibitor of ODC 25 , into the culture medium strongly suppresses neurite extension ${ }^{31}$.

In the present study, we have further explored the correlation between the ODC increase and optic nerve regeneration by treating fish with a specific irreversible inhibitor of ODC, $\alpha$-difluoromethylornithine (DFMO) ${ }^{24}$ and then examining retinal tubulin

\footnotetext{
* Present address: Department of Physiology, Keio University School of Medicine, Shinjuku, Tokyo, Japan.

** Present address: Department of Biochemistry, 1st Medical School, University of Naples, via Constantinopoli 16, 80138 Naples, Italy.

*** To whom correspondence should be addressed.
} 
labeling, neurite extension in culture and recovery of function in vivo.

\section{MATERIALS AND METHODS}

\section{Animals}

Goldfish (Carassius auratus, Ozark Fisheries, Stoutland, MO), $6-7 \mathrm{~cm}$ in body length, were housed in 15 gallon aerated tanks and maintained at $21 \pm 1{ }^{\circ} \mathrm{C}$ except as noted. Intraorbital crush of the right optic nerve was performed as previously described ${ }^{8}$. Crush and enucleation procedures were performed under Finquel (Ayerst) anesthesia.

\section{DFMO treatment}

Thirty microliters of $5 \%(\mathrm{w} / \mathrm{v})$ DFMO ( $\mathrm{pH}$ adjusted to 7.0 with $\mathrm{NaOH}$ ) was injected intraperitoneally. In another series of experiments, fish were maintained in various concentrations $(0.1-1.0 \%)$ of DFMO solution ( $\mathrm{pH} 7.0$ ) for $10-11$ days. The DFMO solution was exchanged once, at 5 days PC. DFMO was the generous gift of Dr. P. McCann, Merrell Laboratories, Cincinnati, $\mathrm{OH}$.

\section{$O D C$ and polyamine assay}

Pooled retinas (5-6) were homogenized in $1 \mathrm{ml}$ of $50 \mathrm{mM}$ Tris- $\mathrm{HCl}$ (pH 7.6) containing $1 \mathrm{mM}$ dithiothreitol and $100 \mu \mathrm{M}$ pyridoxal phosphate. The homogenates were centrifuged at $30,000 \mathrm{~g}$ for $20 \mathrm{~min}$ and the resulting supernatant fractions were used for ODC assay measured by release of ${ }^{14} \mathrm{CO}_{2}$ from labeled ornithine $(100 \mu \mathrm{M}, 0.5 \mu \mathrm{Ci})$ as previously described $^{13}$. Protein was determined by the method of Lowry et al.17.

For polyamine analysis, the TCA supernatant $(10 \% \mathrm{TCA})$ from 10 pooled retinas was washed with ether, derivatized with benzoyl chloride ${ }^{28}$, then subjected to HPLC (Waters Associates, Framingham, $\mathrm{MA} ; \mu$ Bondpak $\mathrm{C} 18$ column) ${ }^{27}$. Following elution with $60 \%$ methanol (flow rate $2.0 \mathrm{ml} / \mathrm{min}$ ), the absorbance was measured at $254 \mathrm{~nm}$ and percent recovery was $61 \%, 50 \%$, and $71 \%$ for putrescine, spermidine, and spermine, respectively.

\section{Tubulin labeling}

Retinas were removed from control or DFMOtreated fish at 10 days following right optic nerve crush, then incubated for $1 \mathrm{~h}$, in duplicate groups of
5 , in the medium of Dunlop et al. ${ }^{4}$ with either L[methyl $\left.-{ }^{3} \mathrm{H}\right]$ methionine or $\mathrm{L}-\left[{ }^{35} \mathrm{~S}\right]$ methionine (Amersham, $91 \mathrm{Ci} / \mathrm{mmol}$ ), as previously described ${ }^{8}$. Matched groups of left $\left(\left[{ }^{3} \mathrm{H}\right]\right.$ methionine $)$ and right ([ $\left.{ }^{35} \mathrm{~S}\right]$ methionine) retinas were pooled and homogenized in $0.4 \mathrm{ml}$ of $0.0625 \mathrm{M}$ Tris- $\mathrm{HCl}(\mathrm{pH} \mathrm{6.8),}$ mM EDTA, I mM phenylmethylsulfonylfluoride. The $100,000 \mathrm{~g}$ supernatant obtained following centrifugation of each homogenate was brought to a final concentration of $1 \%$ in SDS and $8 \mathrm{M}$ in urea prior to 1- or 2-dimensional SDS-slab gel electrophoresis ${ }^{26}$. Gels were fixed and stained, then $1 \mathrm{~mm}$ slices of 1-dimensional gels or the major stained spots, including the tubulin subunits, on 2-dimensional gels were cut out, placed in vials and dissolved with hydrogen peroxide for determination of the ${ }^{35} \mathrm{~S} /{ }^{3} \mathrm{H}$ ratio. The double label ratio for total proteins varied from 0.6 to 2.1 among the various paired samples, and the increase in tubulin labeling for each pair was calculated after normalization. For radioautography, stained dried gels were placed in contact with Kodak XRP-5 X-ray film for 1-2 weeks.

\section{Retinal explant culture}

At 11 days following right optic nerve crush, retinas were removed from the right eye of control or DFMO-treated fish, cut into $500 \mu \mathrm{m}$ squares with a Mcllwain tissue chopper and explanted into polyL-lysine coated dishes as previously described ${ }^{9,15}$. In some experiments, DFMO $(10 \mathrm{mM})$ or diaminopropane $(1 \mathrm{mM})$ was added to the culture medium at the time of explantation. Neuritic outgrowth (neuritic growth index, NGI) was estimated after 6 days in vitro $^{16}$. Briefly, average neurite length was measured in $500 \mu \mathrm{m}$ units, then multiplied by an estimate of the neuritic density on an arbitrary scale of 1-4.

\section{Recovery of vision}

Goldfish were kept in individual plastic containers $(13 \times 18 \times 9 \mathrm{~cm})$ at $25^{\circ} \mathrm{C}$ throughout the experiment. The left eye was enucleated 7 days prior to crush of the right optic nerve. All fish were given 20 trial sessions of shock-avoidance training in a shuttlebox ${ }^{33} 4$ days and 3 days prior to crush. Each trial took $1 \mathrm{~min}$ and consisted of $15 \mathrm{~s}$ of light (conditioned stimulus, CS), followed by $20 \mathrm{~s}$ of light plus repetitive shock (every $2.5 \mathrm{~s}$; unconditioned stimu- 
lus, US), followed by darkness until the onset of the next trial, so that the intertrial interval (ITI) was $25 \mathrm{~s}$ or longer. Avoidance (crossing within $15 \mathrm{~s}$ of light onset) or escape responding terminated the trial. After the second training session fish were assigned to the various experimental groups. Testing following crush differed in the following ways: avoidance responses were recorded during the final $15 \mathrm{~s}$ of ITI preceding a trial, as well as during the $15 \mathrm{~s}$ CS period. The US interval was maintained at $20 \mathrm{~s}$ but with only one shock given at the onset. The ITI was varied pseudo-randomly from 50 to $90 \mathrm{~s}$ to preclude learning of the task by timing. Each testing session consisted of 10 such trials. Fish were retested twice weekly. They were fed and their tank water changed 2-4 times per week. The shuttlebox was equipped with photodetectors and was controlled by a SYM-1 microcomputer. Preliminary experiments indicated that totally blind fish which had been trained previously made few and roughly equal numbers of crossings in the $15 \mathrm{~s}$ dark interval preceding the light onset as they did in the $15 \mathrm{~s}$ period in the light. Previously trained fish with one intact eye, on the other hand, showed about $8 \%$ crossing during the dark period and about $80 \%$ crossing (avoidance responding) during the light presentation. The criterion for recovery of vision used was 2 consecutive sessions in which crossings in the light exceeded crossings in the dark by at least 3 responses.

\section{Histology}

$\mathrm{PC}$ and $\mathrm{N}$ retinas were removed from 11-day PC fish which were maintained either in the presence or absence of $0.1 \%$ DFMO solution. Retinas were fixed in Bouin's solution for 7 days, dehydrated, embedded in Paraplast and cut into $6 \mu \mathrm{m}$ sections. Sections were stained with $0.01 \%$ Cresyl violet acetate.

\section{RESULTS}

\section{Effect of DFMO injection on retinal ODC}

To suppress retinal ODC activity, fish were injected intraperitoneally with DFMO. Preliminary experiments showed that the $\mathrm{LD}_{50}$ for DFMO was approximately $5 \mathrm{mg}$ and in subsequent experiments $1.5 \mathrm{mg}$ was used. Fig. 1 shows the retinal ODC activity in the non-crushed control fish following a single injection of DFMO. ODC activity was maxi-

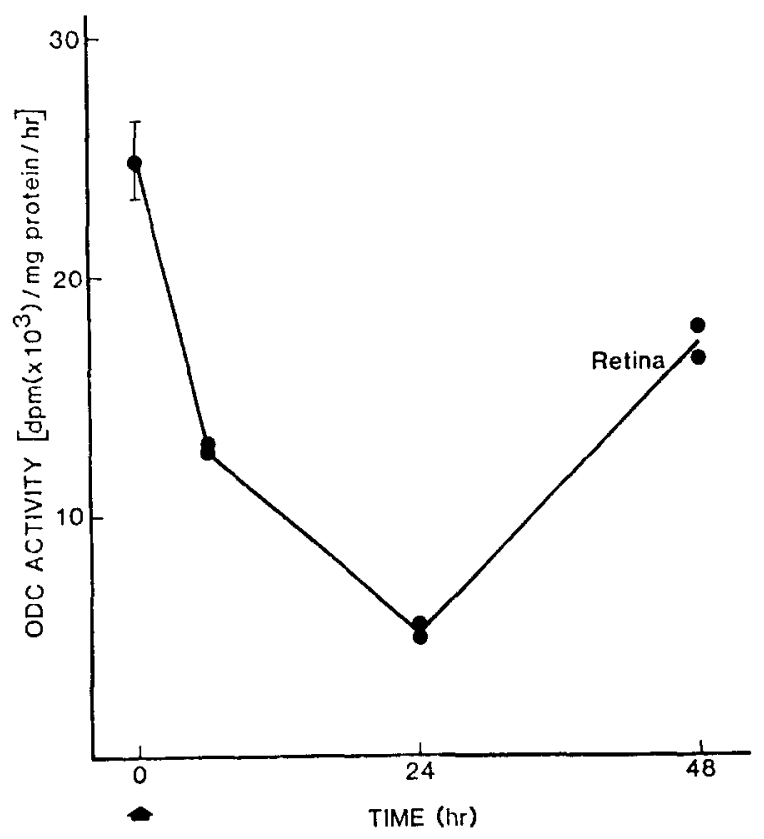

Fig. 1. Retinal ODC activity in unoperated control fish following a single injection of DFMO. DFMO $(1.5 \mathrm{mg})$ was injected intraperitoneally and retinal ODC was measured 6 , 24 and $48 \mathrm{~h}$ after the injection. Each point represents the value obtained for 6 pooled retinas. The initial activity \pm S.E.M. was obtained from 6 groups of 6 pooled retinas.

mally inhibited ( $20 \%$ of control) at $24 \mathrm{~h}$ after the injection and was partially restored thereafter to $70 \%$ of control values by $48 \mathrm{~h}$. As shown below, multiple injections were more effective in reducing retinal ODC.

The increase in retinal ODC activity following unilateral optic nerve crush became maximal by day 5 and sharply returned to the control level by day $6^{613}$. To suppress this temporal increase in retinal ODC activity, multiple injections (30 $\mu \mathrm{l}$ of $5 \%$ DFMO) were given at the time of crush, at 2 days $P C$ and at 4 days PC (Fig. 2). Maximal inhibition ( $10 \%$ of control) was obtained at 5 and 6 days PC, with a return to normal ODC levels by 14 days. Multiple injections of DFMO completely prevented the sharp increase in retinal ODC following optic nerve crush.

Effect of DFMO injection on tubulin labeling and retinal explant neuritic outgrowth

As a response to lesion of the optic nerve, retinal ganglion cells exhibit an increase in the synthesis of the microtubule subunits ${ }^{2,8}$. In order to determine if 


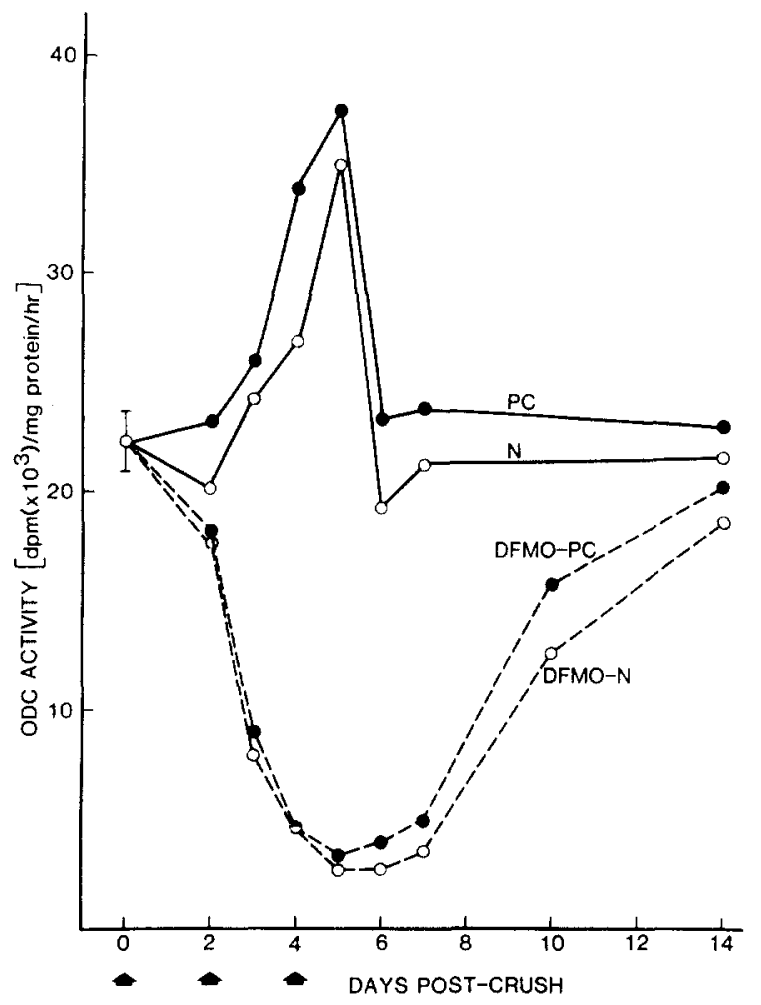

Fig. 2. Retinal ODC activity in saline-treated or DFMOtreated fish. The right optic nerve was crushed intraorbitally. DFMO (1.5 mg) was injected intraperitoneally at the time of crush, 2 days PC and 4 days PC (arrow). Control fish were injected with saline. Each point represents the mean value of 2 groups of 6 pooled retinas. The initial activity is the mean \pm S.E.M. of 4 groups of 6 pooled retinas. PC, saline-treated PC retinas; $\mathrm{N}$, saline-treated $\mathrm{N}$ retinas; DFMO-PC, DFMOtreated $\mathrm{PC}$ retinas; DFMO-N, DFMO-treated $\mathrm{N}$ retinas.

the enhancement in ODC activity was a prerequisite for the increased synthesis of tubulin, double labeling experiments were carried out with retinas from saline-treated fish or from fish injected with DFMO as described above. Retinas were removed and incubated with $\left[{ }^{35} \mathrm{~S}\right]$ or $\left[{ }^{3} \mathrm{H}\right]$ methionine at 10 days following optic nerve crush, a time at which the enhanced tubulin labeling is readily detectable, while the ODC activity of DFMO-treated fish remains well below control levels. In 3 separate experiments (Table I), DFMO treatment was found not to block the increase in tubulin labeling seen in postcrush retinas. Comparison of the ${ }^{35} \mathrm{~S} /{ }^{3} \mathrm{H}$ ratio of the tubulin subunits after 2-dimensional gel electrophoresis (not shown) confirmed this conclusion.

Even though the elevation in retinal ODC activity appears unnecessary for the increased tubulin la-
TABLE I

Effect of DFMO treatment on tubulin labeling and neurite outgrowth

Tubulin labeling: normalized ${ }^{35} \mathrm{~S} /{ }^{3} \mathrm{H}$ ratio. Each value is the average of duplicate determinations. Retinal explant neurite growth index: mean $t$ S.E.M. of 3-5 dishes, each containing 16 explants.

\begin{tabular}{lll} 
& $\begin{array}{c}\text { Tubulin labeling } \\
P C / N\left({ }^{5} S /{ }^{3} \mathrm{H}\right)\end{array}$ & $\begin{array}{l}\text { Retinal explant neurite } \\
\text { growth index }\end{array}$ \\
\hline $\begin{array}{l}\text { Experiment I } \\
\text { Control }\end{array}$ & 1.34 & \\
DFMO 1.84 & $3.25 \pm 0.16$ \\
Experiment II & & $3.75 \pm 0.26^{*}$ \\
Control & 1.34 & $4.38 \pm 0.76$ \\
DFMO 1.32 & $3.63 \pm 0.50^{*}$ \\
Experiment III & \\
Control 1.62 & $3.56 \pm 0.35$ \\
DFMO & 2.05 & $3.52 \pm 0.30^{*}$
\end{tabular}

* Not significantly different from the control by Student's $t$-test.

beling, it might still be a prerequisite for other events in the retinal ganglion cell which are required for regrowth of the axon. This possibility was examined by assessing the effect of DFMO treatment in vivo on the subsequent ability of retinal explants to grow neurites in vitro. The latter has been shown to be dependent upon prior lesion of the optic nerve, with optimal neuritic outgrowth occurring if retinas are explanted at 10-15 days following optic nerve crush (ref. 16). Retinas from saline or DFMO-treated fish were explanted at 11 days post-crush and the extent of neuritic outgrowth was estimated after 6 days in vitro (Table I). No effect of DFMO treatment was observed. In a separate series of experiments, addition of DFMO $(10 \mathrm{mM})$ to the culture medium, did not significantly affect neuritic outgrowth $(102 \%$ of control), even though ODC activity was inhibited by $70 \%$ under these conditions ${ }^{31}$. Diaminopropane (1 $\mathrm{mM})$ produced a marked inhibition of the NGI $\left(78 \%\right.$ ) as previously noted ${ }^{31}$.

\section{Recovery of vision}

Recovery of vision was measured by avoidance responses. A preliminary experiment showed that the surgical procedure and injection had no effect on performance. Control fish began to achieve the criterion for vision recovery at 14 days $\mathrm{PC}$, and $80 \%$ of 


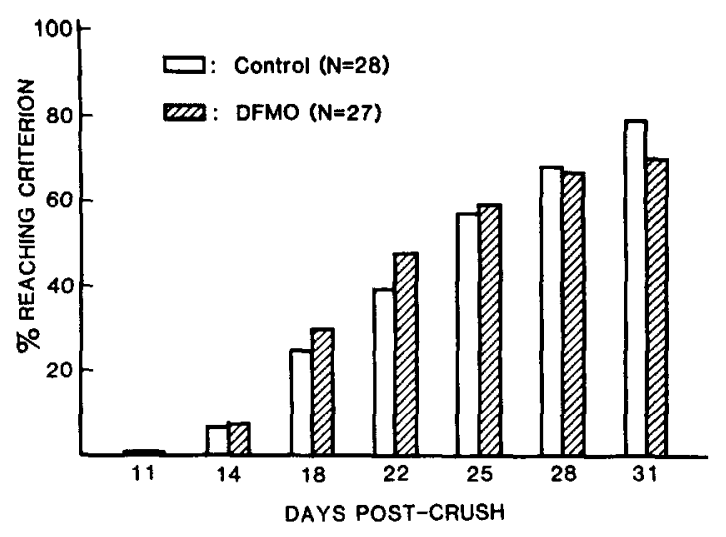

Fig. 3. Recovery of vision. Saline or DFMO $(1.5 \mathrm{mg})$ was injected intraperitoneally at the time of optic nerve crush as well as 2 and 4 days later. Recovery of vision was examined behaviorally as described in Materials and Methods.

the fish had reached the criterion by 31 days PC. The DFMO-treated fish showed almost the same pattern as control fish (Fig. 3). Thus, the rate of return of vision was also unaffected by DFMO treatment.

\section{Effect of DFMO on polyamine content}

From the above experiments a requirement for enhanced ODC activity in regeneration appears to be ruled out, but the possible function of polyamines in the process still required evaluation. Therefore, the effect of DFMO on polyamine content in the retina was also examined. DFMO was injected into non-crushed control fish twice (day 0 and day 2) and retinal polyamine concentration was measured at day 4. Putrescine content in the control retina was $0.59 \pm 0.04 \mathrm{nmol} / \mathrm{retina}$ and DFMO injection significantly reduced the putrescine content by $39 \%(0.36$ $\pm 0.02 \mathrm{nmol} / \mathrm{retina})$. However, the DFMO injection did not affect the content of the other polyamines, spermidine and spermine.

\section{DFMO administration via tank water}

It could be argued that the lack of effect of DFMO on the regeneration process reflects an incomplete suppression of polyamines or a possible fluctuation of ODC activity between each injection. Since inhibitory effects on ODC in rats and mice can be achieved by administration of DFMO as a $2-3 \%$ solution in the drinking water ${ }^{5,18}$, fish were maintained for 4 days in solutions of DFMO in an attempt to further suppress ODC activity and putrescine content (Fig. 4). Although inhibition of

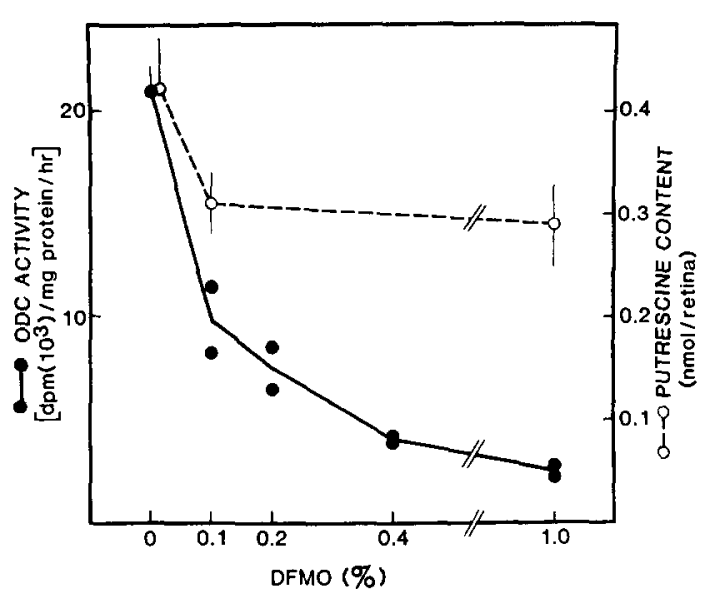

Fig. 4. Retinal ODC activity and putrescine content in fish maintained in tanks containing various concentrations of DFMO. Six pooled retinas were used for each ODC assay. Putrescine values represent mean \pm S.E.M. of 3-4 groups of 10 pooled retinas.

ODC activity increased from 53 to $88 \%$ when the DFMO concentration was raised from $0.1 \%$ to $1 \%$, there was not a parallel decline in putrescine content. At both concentrations of DFMO, the putrescine level was decreased by only about $30 \%$, a value similar to that attained by multiple DFMO injections.

Fish maintained in $0.1 \%$ DFMO solution for 10 days from the time of nerve crush were also examined to determine the effect of DFMO on tubulin labeling, neuritic outgrowth and vision recovery. The same results seen in the DFMO injection experiments were obtained: DFMO solution $(0.1 \%)$ did not affect tubulin labeling enhancement, neuritic growth index, or recovery of vision (data not shown). Histological examination of the retinas from DFMO-treated ( $0.1 \%$ solution) and control fish also indicated no effect of suppression of ODC on the ganglion cell response to axotomy (Fig. 5). Effects of higher concentrations were not examined.

\section{DISCUSSION}

A number of studies suggest that polyamines play an essential role in a variety of rapid tissue growth processes in which macromolecular synthesis is enhanced. While the precise relation of the polyamines to such cellular processes remains unknown, hypotheses generally invoke the structural stability offer- 


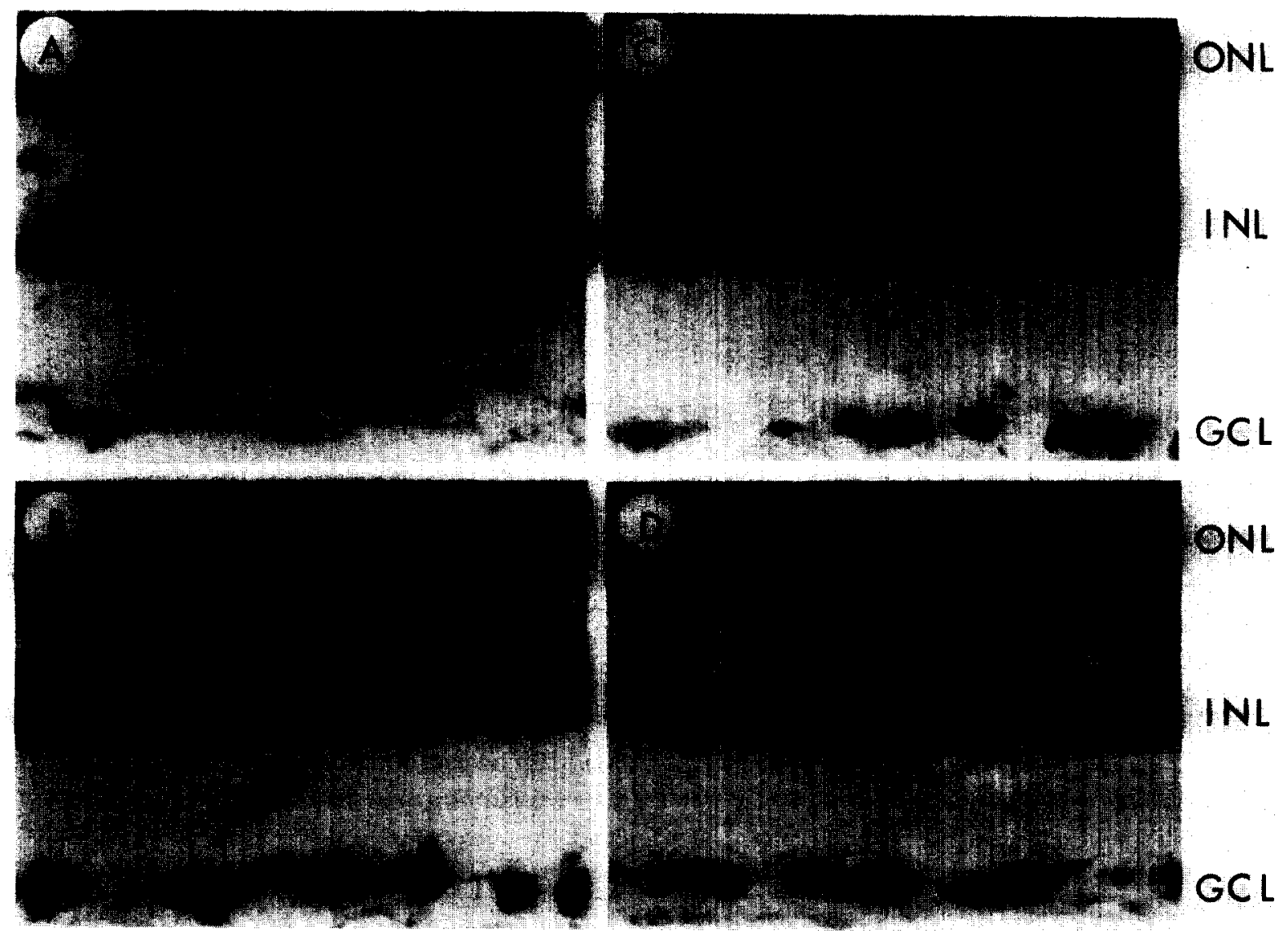

Fig. 5. Light micrographs of retinas obtained from 11-day PC fish. Normal (A) and post-crush (B) retinas from untreated fish; normal (C) and post-crush (D) retinas from fish maintained in $0.1 \%$ DFMO solution. DFMO does not block the increase in ganglion cell size, nuclear eccentricity or nucleolar hypertrophy seen following crush. ONL, outer nuclear layer; INL, inner nuclear layer; GCL, ganglion cell layer. Note prominence of GC nuclei and nucleoli in B and D.

ed by the high affinity of these polybasic cations for acidic functions of nucleic acids.

Possible roles of polyamines in maturation or in differentiation processes in the nervous system have also been suggested. For example, high activity of ODC is demonstrated in rat or mouse olfactory tissue in which the chemoreceptor neurons continuously differentiate, mature, die and are replaced by immature cells ${ }^{29}$. A high level of ODC was also reported in the developing retina during the first 12 days of life when cellular differentiation is taking place $^{20}$. A possible role in nervous system has also been suggested by the fact that the axonal transport of some polyamines is enhanced in the newly regenerated optic nerve in goldfish ${ }^{10}$.

The importance of polyamines for such cellular processes has recently been emphasized in studies using DFMO, a specific irreversible inhibitor of
ODC, which alkylates the active site of the enzyme (ref. 24). Inhibition of ODC by DFMO has been found to decrease the rate of cell replication ${ }^{21}$ and survival of cultured cells ${ }^{34}$ and to arrest embryonic development when administered to pregnant mice ${ }^{5}$.

In the present study, experiments were performed to determine if the striking enhancement in retinal ODC activity following optic nerve crush mediates other biochemical events in the retina, such as increased synthesis of tubulin, and if it is necessary for axon regrowth. Although administration of DFMO, by either of two routes, eradicated the temporal increase in ODC activity following optic nerve crush, it did not affect the enhancement of tubulin synthesis, neurite outgrowth, or the rate of recovery of vision. Another retinal marker of regeneration is the uptake of uridine, shown to be energy-dependent and rate-limited by uridine kinase ${ }^{12,14}$. DFMO ad- 
ministration produced some variability in uridine uptake in both $\mathrm{N}$ and $\mathrm{PC}$ retinas, but comparisons (not shown) gave no indication that either intraocular injection $(1.5 \mathrm{mg})$ or $0.1 \%$ solution of DFMO administered through the water had any effect on the enhancement of uridine metabolism. These results, taken together, argue against an association between the increase in ODC activity and optic nerve regeneration.

The lack of effect of ODC inhibition on nerve growth, either in vivo or in vitro, relates to the findings of Greene and McGuire? who showed that nerve growth factor (NGF) promoted the differentiation and survival of rat PC-12 cells and also induced ODC activity. Treatment with diaminopropane, a blocker of ODC synthesis, did not affect NGF-dependent survival or stimulation of neurite outgrowth from these cells. Although we recently reported that addition of diaminopropane and DFMO into the culture medium suppressed ODC activity and blocked neurite extension ${ }^{31}$, the present experiments show that $10 \mathrm{mM}$ DFMO does not affect neurite extension from retinal explants. Therefore, diaminopropane may have affected neuritic outgrowth by non-specific toxicity or by interference with attachment of the explant to the poly-L-lysine substratum.

The relatively minor decrease in polyamine content produced by DFMO in the present studies, relative to the marked decrease in ODC activity, may reflect the long biological half-lives of polyamines ${ }^{32}$. When $\left[{ }^{14} \mathrm{C}\right]$ spermine is injected into the goldfish eye, more than $50 \%$ of the radioactivity is recovered as sper-

\section{REFERENCES}

1 Burrell, H. R., Dokas, L. A. and Agranoff, B. W., RNA metabolism in the goldfish retina during optic nerve regeneration, J. Neurochem., 31 (1978) 289-298.

2 Burrell, H. R., Heacock, A. M., Water, R. D. and Agranoff, B. W., Increased tubulin messenger RNA in the goldfish retina during optic nerve regeneration, Brain Res., 168 (1979) 628-632.

3 Dokas, L. A., Kohsaka, S., Burrell, H. R. and Agranoff, B. W., Uridine metabolism in the goldfish retina during optic nerve regeneration: whole retina studies, $J$. Neurochem., 36 (1981) 1160-1165.

4 Dunlop, D. S., Van Elder, W. and Lajtha, A., Measurement of rates of protein synthesis in rat brain slices, $J$. Neurochem., 22 (1974) 821-830.

5 Fozard, J. R., Part, M.-L., Prakash, N. J., Grove, J., Schechter, P. J., Sjoerdsma, A. and Koch-Wester, J., mine, even after 6 days ${ }^{10}$. In addition, spermidine $\mathrm{N}$ acetyltransferase, which is reported to accelerate the degradation of spermidine to putrescine, may serve to limit depression of putrescine levels under certain conditions $^{22}$. Also, DFMO treatment has been found to cause a compensatory increase in S-adenosylmethionine decarboxylase activity5,19,21, thus enhancing synthesis of spermidine and spermine. It remains likely then that the $90 \%$ block of ODC activity achieved may have been insufficient to interfere with polyamine function. Still greater inhibition of ODC, possibly in combination with inhibitors of other biosynthetic steps, might lower polyamine levels to the point that effects on regeneration would be observed. Since ODC turns over rapidly, DFMO must be administered frequently, and for this reason addition of the agent to the fish tanks seemed an ideal route. The doses used, however, proved less effective than the injection route. The use of larger amounts of the drug in the tank water is currently impracticable. Preliminary toxicity studies indicate that fish can survive in a $2 \%$ DFMO solution, although doses over $3 \%$ are acutely toxic.

\section{ACKNOWLEDGEMENTS}

We thank Ms. Marianne Lewis and Ms. Judith Wye-Dvorak for their technical assistance.

This work was supported by NIH Grants NS 13743 and $\mathrm{MH}$ 12506. S.K. was supported by the Fukuzawa Memorial Grant of Keio University, Tokyo, Japan.

L-Ornithine decarboxylase: an essential role in early mammalian embryogenesis, Science, 208 (1980) 505-508.

6 Grafstein, B. and McQuarrie, I. G., Role of the nerve cell body in axonal regeneration. In C. W. Cotman (Ed.), Neuronal Plasticity, Raven Press, New York, 1978, pp. 155-195.

7 Greene, L. A. and McGuire, J. C., Induction of ornithine decarboxylase by nerve growth factor dissociated from effects on survival and neurite outgrowth, Nature (Lond.), 276 (1978) 191-194.

8 Heacock, A. M. and Agranoff, B. W., Enhanced labeling of a retinal protein during regeneration of optic nerve in goldfish, Proc. nat. Acad. Sci. (U.S.A.), 73 (1976) 828-832.

9 Heacock, A. M. and Agranoff, B. W., Clockwise growth of neurites from retinal explants, Science, 198 (1977) 64-66.

10 Ingoglia, N. A., Sturman, J. A. and Eisner, R. A., Axonal 
transport of putrescine, spermidine and spermine in normal and regenerating goldfish optic nerves, Brain Res., 130 (1977) 433-445.

11 Janne, J., Poso, H. and Raina, A., Polyamines in rapid growth and cancer, Biochim. biophys. Acta, 473 (1978) 241-293.

12 Kohsaka, S., Dokas, L. A. and Agranoff, B. W., Uridine metabolism in the goldfish retina during optic nerve regeneration: cell-free preparations, $J$. Neurochem., 36 (1981) 1166-1174.

13 Kohsaka, S., Schwartz, M. and Agranoff, B. W., Increased activity of ornithine decarboxylase in goldfish following optic nerve crush, Develop. Brain Res., 1 (1981) 391-402.

14 Kohsaka, S., Masyuk, A. I. and Agranoff, B. W., Nucleoside metabolism in the goldfish retina following optic nerve crush. In Eighth International Meeting of the Society for Neurochemistry, Nottingham, England, 1981, p. 396, abstract.

15 Landreth, G. E. and Agranoff, B. W., Explant culture of adult goldfish retina: effect of prior optic nerve crush, Brain Res., 118 (1976) 299-303.

16 Landreth, G. E. and Agranoff, B. W., Explant culture of adult goldfish retina: a model for the study of CNS regeneration, Brain Res., 161 (1979) 39-53.

17 Lowry, O. H., Rosebrough, N. J., Farr, A. L. and Randall, R. J., Protein measurement with the Folin phenol reagent, J. biol. Chem., 193 (1951) 265-275.

18 Luk, G. D., Marton, L. J. and Baylin, S. B., Ornithine decarboxylase is important in intestinal mucosal maturation and recovery from injury in rats, Science, 210 (1980) 195-198.

19 Luk, G. D., Goodwin, G., Marton, L. J. and Baylin, S. B., Polyamines are necessary for the survival of human small-cell lung carcinoma in culture, Proc. nat. Acad. Sci. (U.S.A.), 78 (1981) 2355-2358.

20 Macaione, S. and Calatroni, A., Polyamines and ornithine decarboxylase activity in the developing rat retina, Life Sci., 23 (1978) 683-690.

21 Mamont, P. S., Duchesne, M.-C., Grove, J. and Bey, P., Anti-proliferative properties of DL- $a$-difluoromethyl ornithine in cultured cells. A consequence of the irreversible inhibition of ornithine decarboxylase, Biochem. Biophys. Res. Commun., 81 (1978) 58-66.

22 Matsui, I., Wiegand, L. and Pegg, A. E., Properties of spermidine $\mathrm{N}$-acetyltransferase from livers of rats treated with carbon tetrachloride and its role in the conversion of spermidine into putrescine, J. biol. Chem., 256 (1981) 2454-2459.

23 Maudsley, D., Regulation of polyamine biosynthesis, Biochem. Pharmacol., 28 (1979) 153-161.

24 Metcalf, B. W., Bey, P., Danzin, C., Jung, M. J., Casara, P. and Vevert, J. P., Catalytic irreversible inhibition of mammalian ornithine decarboxylase (E.C. 4.1.1.17) by substrate and product analogs, J. Amer. Chem. Soc., 100 (1976) 2551-2553.

25 McCann, P., Regulation of ornithine decarboxylase in eukaryotes. In J. M. Ganzos (Ed.), Polyamines in Biomedical Research, John Wiley, New York, 1980, pp. 109-123.

26 O'Farrell, P. H., High resolution two-dimensional electrophoresis of proteins, J. biol. Chem., 250 (1975) 4007-4021.

27 Porta, R., Doyle, R. L., Tatter, S. B., Wilens, T. E., Schatz, R. A. and Sellinger, O. Z., The biosynthesis of polyamines in the brain of audiogenic seizure-susceptible and -resistant Deermice, J. Neurochem., 37 (1981) 123-129.

28 Redmond, J. N. and Tseng, A., High-pressure liquid chromatographic determination of putrescine, cadaverine, spermidine and spermine, J. Chromatography, 170 (1979) 479-481.

29 Rochel, S. and Margolis, F. L., The response of ornithine decarboxylase during neuronal degeneration and regeneration in olfactory epithelium, $J$. Neurochem., 35 (1980) $850-860$.

30 Russell, D. H., Ornithine decarboxylase as a biological and pharmacological tool, Pharmacology, 20 (1980) 117129.

31 Schwartz, M., Kohsaka, S. and Agranoff, B. W., Ornithine decarboxylase activity in retinal explants of goldfish undergoing optic nerve regeneration, Develop. Brain Res. 1 (1981) 403-413.

32 Snyder, S. H., Kreuz, D. S., Medina, V. J. and Russell, D. H., Polyamine synthesis and turnover in rapidly growing tissues, Ann. N.Y. Acad. Sci., 171 (1970) 749-771.

33 Springer, A. D., Schoel, W. M., Klinger, P. D. and Agranoff, B. W., Anterograde and retrograde effects of electroconvulsive shock and of puromycin on memory formation in the goldfish, Behav. Biol., 13 (1975) 467-481.

34 Veldhuis, J. D. and Hammond, J. M., Role of ornithine decarboxylase in granulosa-cell replication and steroidogenesis in vitro, Biochem. Biophys. Res. Commun., 91 (1979) 770-777. 